\title{
Éveline Caduc, La maison des chacals
}

Ilaria Vitali

\section{(2) OpenEdition}

\section{Journals}

\section{Edizione digitale}

URL: http://journals.openedition.org/studifrancesi/9357

DOI: 10.4000/studifrancesi.9357

ISSN: 2421-5856

\section{Editore}

Rosenberg \& Sellier

\section{Edizione cartacea}

Data di pubblicazione: 1 juin 2008

Paginazione: 231-232

ISSN: 0039-2944

\section{Notizia bibliografica digitale}

Ilaria Vitali, «Éveline Caduc, La maison des chacals», Studi Francesi [Online], 154 (LII | I) | 2008, online dal 30 novembre 2015, consultato il 09 janvier 2021. URL: http://journals.openedition.org/studifrancesi/ 9357 ; DOI: https://doi.org/10.4000/studifrancesi.9357

\section{Questo documento è stato generato automaticamente il 9 janvier 2021.}

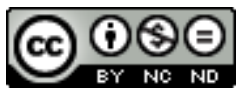

Studi Francesi è distribuita con Licenza Creative Commons Attribuzione - Non commerciale - Non opere derivate 4.0 Internazionale. 


\title{
Éveline Caduc, La maison des chacals
}

\author{
Ilaria Vitali
}

\section{NOTIZIA}

ÉVELINE CADUC, La maison des chacals, Monaco, Éditions du Rocher, 2006, pp. 239.

1 Da Assia Djebar a Gillo Pontecorvo, la guerra d'Algeria è stata al centro di prove letterarie e cinematografiche di grande rilievo. Per cercare di gettare nuova luce sul delicato tema, Éveline Caduc ne riprende la storia in questo romanzo dal titolo $L a$ maison des chacals. Quello dell'autrice è uno sguardo interno, in parte autobiografico, che tiene conto non solo della singolarità della vicenda umana dei personaggi, ma soprattutto del divenire storico, del recupero del passato individuale e collettivo. Il meccanismo narrativo che innesca la narrazione è semplice: il giornalista pied-noir Philippe Jouannet è incaricato da un produttore televisivo di scrivere una sceneggiatura sulla guerra d'Algeria. Dopo averne tracciata la prima parte, ambientata nei pressi di Djémila nel 1955, si trova a corto d'ispirazione e decide di ritornare nel suo paese natale per la prima volta dopo moltissimi anni. Il viaggio lo aiuterà non solo a far luce sulla guerra, ma soprattutto sul suo passato, e in particolare sulla figura del padre, medico all'ospedale Mustapha, ucciso nel 1956 da alcuni fellagha.

2 La storia, costruita en poupées russes, scava nel passato e fa riemergere misteri insoluti. Per rendere conto della molteplicità dei punti di vista all'epoca del conflitto, Éveline Caduc intesse diversi generi letterari, che fanno avanzare la narrazione fino alla soluzione dell'intreccio. In bilico tra racconti, diari intimi e lettere, il romanzo riesce nel tentativo di ricostruire, attraverso le vicissitudini di alcuni personaggi chiave, un affresco più ampio, autentico spaccato di un periodo storico che continua a far discutere. L'explicit svela i protagonisti sotto una nuova luce, rappacificati con il passato al termine della loro quête, e apre allo stesso tempo uno spiraglio di speranza sulla possibilità di convivenza pacifica dei popoli da una riva all'altra del Mediterraneo. Alla luce del suo viaggio - geografico e mentale - Philippe Jouannet rinuncerà all'incarico della sceneggiatura, ma deciderà di scrivere una serie di articoli sull'Algeria di oggi per 
far conoscere all'Europa l'identità di uno dei suoi vicini più prossimi. Come afferma Jouannet: «Et de l'autre côté de la Méditerranée, de l'Orient à 'l'île d'Occident', y compris l'enclave israélienne, je vois une autre communauté dont l'unité n'est pas encore achevée et qui est la voisine de l'Europe» (p. 233). Vietandosi di vivere con gli occhi rivolti al passato, Jouannet tornerà in Algeria per dire i sogni e le speranze dei suoi abitanti, quelli dei piccoli artigiani o dei medici, quelli delle donne e dei bambini.

3 Il volume porta in appendice un glossario su alcuni termini dell'arabo algerino indispensabili per la comprensione del testo. 